\title{
Pengaruh Nisbah Jumlah Daun Terhadap Kualitas Buah Jeruk Pamelo (Citrus maxima (Burm.) Merr.)
}

\section{Effect of Leaf-to- Fruit Ratio On the Quality Pummelo (Citrus maxima (Burm.) Merr.)}

Evan Yonda Pratama dan Slamet Susanto*

\author{
Departemen Agronomi dan Hortikultura, Fakultas Pertanian, Institut Pertanian Bogor \\ (Bogor Agricultural University), J1. Meranti, Kampus IPB Darmaga, Bogor 16680, Indonesia \\ Telp. \& Faks. 62-251-8629353 e-mail agrohort@apps.ipb.ac.id \\ *Penulis Korespondensi : slmtsanto@gmail.com
}

Disetujui : 8 Mei 2018 / Published Online 2 Januari 2019

\begin{abstract}
Pummelo is one of citrus type which is potentially developed in Indonesia. The objective of this research was to obtain information the effect of leaf -to-fruit ratio on the development and quality of pummelo fruit (Citrus maxima (Burm.) Merr.). The experiment was conducted at Cikabayan Experimental Station, IPB Dramaga, Bogor, and Agronomy and Horticulture Postharvest Laboratory of IPB, from January to June 2016. Analysis of fruit weight, fruit softness, total soluble solids (TSS) content and titratable acidity (TA) was held in Postharvest Laboratory, Department of Agronomy and Horticulture, Faculty of Agriculture, IPB. This study used a completely randomized design with single factors, namely leaf-to-fruit ratio that consists of four levels: 50, 100, 200, and 300. The observations consisted of fruit diameter, final fruit weight, final fruit diameter, fruit softness, total soluble solids and titratable acidity. Leaves -to- fruit ratio significantly affected on fruit diameter and fruit weight. Overall leaf-to-fruit ratio did not affect on the TSS, TA, and fruit softness.
\end{abstract}

Keywords: diameter, leaf-to-fruit ratio, pummelo, quality

\begin{abstract}
ABSTRAK
Pamelo merupakan salah satu jenis jeruk yang potensial dikembangkan di Indonesia. Penelitian ini bertujuan untuk mengetahui pengaruh nisbah daun buah terhadap kualitas buah jeruk pamelo (Citrus maxima (Burm.) Merr.). Percobaan dilaksanakan di Kebun Percobaan Cikabayan, IPB Dramaga, Bogor dan Laboratorium Pascapanen Departemen Agronomi dan Hortikultura IPB pada bulan Januari sampai Juni 2016. Analisis bobot buah, kelunakan buah, Padatan Terlarut Total (PTT) dan Total Asam Tertitrasi (TAT) dilaksanakan di Laboratorium Pascapanen, Departemen Agronomi dan Hortikultura, Fakultas Pertanian, IPB. Penelitian ini menggunakan Rancangan Acak Lengkap (RAL) dengan satu faktor yang dicobakan yaitu nisbah jumlah daun:buah yang terdiri dari empat taraf: 50, 100, 200, dan 300 daun. Pengamatan terdiri dari pengamatan diameter buah per minggu, pengamatan bobot akhir buah, pengamatan diameter akhir buah, kelunakan buah, padatan terlarut total serta pengamatan total asam tertitrasi. Nisbah daun buah berpengaruh nyata terhadap diameter buah dan bobot buah. Secara keseluruhan rasio daun buah tidak berpengaruh terhadap padatan terlarut total, total asam tertitrasi dan kelunakan buah.
\end{abstract}

Kata kunci : diameter, kualitas, pamelo, nisbah daun buah 


\section{PENDAHULUAN}

Jeruk Pamelo (Citrus maxima (Burm.) Merr.) merupakan salah satu jenis jeruk yang potensial dikembangkan di Indonesia, karena karakteristiknya yang khas, yaitu berukuran besar, memiliki rasa segar, dan daya simpan yang lama sampai 4 bulan (Susanto 2004). Produksi jeruk dalam negeri masih belum mampu memenuhi kebutuhan konsumsi jeruk, hal ini ditunjukkan oleh nilai Self Sufficiency Ratio (SSR) pada tahun 2010-2014 berkisar 86 sampai 94\%, sehingga Indonesia perlu melakukan impor untuk memenuhi kebutuhan tersebut. Impor jeruk pada tahun 2010-2014 semakin meningkat. Tahun 2012, nilai impor jeruk menduduki proporsi impor buah terbesar di Indonesia, yakni mencapai US\$ 256098000 (Sekjen Kementan, 2013).

Jeruk pamelo ditetapkan sebagai salah satu jenis komoditas unggulan tanaman buah Direktorat Jenderal Hortikultura sesuai Keputusan Menteri Pertanian No. 511/Kpts/PD.310/9/2006. Pangestuti et al. (2004) dan Rahayu (2012) menyatakan bahwa kultivar jeruk pamelo yang banyak dibudidayakan di Indonesia adalah jeruk pamelo kultivar Nambangan karena memiliki masa simpan yang relatif panjang dan berpotensial tidak berbiji. Selain itu, kandungan vitamin $\mathrm{C}$ pada kultivar Nambangan tidak turun secara nyata selama 8 minggu setelah penyimpanan (MSP). Toh et al. (2013) menyatakan bahwa jeruk pamelo mengandung beberapa senyawa antioksidan yang cukup tinggi, seperti senyawa fenol dan flavonoid.

Buah merupakan salah satu sink terpenting yang membutuhkan keberlanjutan ketersediaan asimilat selama masa pertumbuhan. Buah jeruk pamelo berukuran besar sehingga membutuhkan ketersediaan asimilat dalam jumlah yang besar pula. Informasi tentang hubungannya source-sink pada jeruk pamelo Indonesia masih sedikit, sehingga diperlukan observasi tentang hal tersebut. Ryugo (1988) menyatakan bahwa source-sink dapat dimanipulasi dengan pengaturan tingkat nisbah jumlah daun buah. Pengaturan nisbah jumlah daun:buah merupakan salah satu dasar untuk memperbaiki kualitas buah yang diharapkan. Yuan et al. (2005) dan Rattanapong (2001) melaporkan bahwa nisbah jumlah daun:buah mampu meningkatkan kualitas buah jeruk "Valencia" dan jeruk pamelo cv. Hom Hat Yai.

Daun dan semua jaringan tanaman yang berfotosintesis adalah source (Snyder dan Carlson, 1993), bahan kering yang dihasilkan dari fotosintesis kemudian di translokasikan melalui floem ke bagian tanaman yang membutuhkan sink. Daun mampu menopang kebutuhan buah dalam menyediakan asimilat untuk pertumbuhan dan perkembangan buah sampai daun tersebut rontok. Buah merupakan salah satu organ sink untuk asimilat selama periode pertumbuhan dan perkembangan buah, sehingga jumlah buah merupakan komponen ukuran atau besaran sink. Menurut Egli (1999), hasil suatu tanaman dapat dibatasi oleh aktivitas sumber (source) seperti fotosintesis pada daun atau oleh keberadaan sink yang menggunakan fotosintat hasil source. Proses fotosintesis yang terjadi pada daun, menghasilkan asimilat yang digunakan untuk pertumbuhan buah dan juga berkontribusi terhadap kualitas buah.

Permasalahan budidaya jeruk pamelo tidak hanya pada kebutuhan asimilat dalam perkembangan buah melainkan juga kualitas eksternal buah. Perbaikan kualitas eksternal buah yang paling utama adalah penampilan buah. Penampilan buah dipengaruhi oleh kerusakan pada kulit buah. Kerusakan tersebut disebabkan adanya serangan hama dan penyakit. Kerusakan tersebut dapat ditanggulangi dengan melakukan pemberongsongan dengan menggunakan plastik. Pemberongsongan sebaiknya dilakukan dengan menggunakan plastik berwarna bening dan kuning karena dapat meningkatkan kemanisan dan indeks kematangan buah jeruk pamelo (Kalsum, 2015).

Hasil penelitian Kalsum (2015) menyatakan bahwa setiap buah jeruk pamelo kultivar Nambangan membutuhkan minimal 50 daun untuk mendukung perkembangan buah serta menghasilkan kualitas terbaik. Sobir dan Napitupulu (2010) menyatakan bahwa untuk mendapatkan hasil yang optimum pada setiap $\mathrm{kg}$ buah durian, umumnya membutuhkan 100 helai daun. Berdasarkan hal diatas, maka upaya memperbaiki kualitas buah jeruk pamelo sangat diperlukan untuk meningkatkan kualitas internal dan eksternal buah melalui pengaturan jumlah nisbah daun buah.

\section{BAHAN DAN METODE}

Penelitian ini dilakukan di Kebun Percobaan Cikabayan University Farm, Darmaga, Bogor, Jawa Barat. Penelitian dilakukan selama 5 bulan, dimulai dari bulan Januari hingga Juni 2016. Analisis bobot buah, kekerasan buah, Padatan Terlarut Total (PTT) dan Total Asam Tertitrasi (TAT) akan dilaksanakan di Laboratorium Pascapanen, Departemen Agronomi dan Hortikultura, Fakultas Pertanian, IPB. Bahan yang digunakan dalam penelitian ini meliputi tanaman jeruk pamelo hasil okulasi yang telah berumur 5 tahun dan telah berproduksi untuk kedua kalinya, plastik pemberongsong, pupuk 
NPK 15:15:15, pupuk kandang dan senyawa kimia dalam analisis jeruk pamelo. Tinggi tanaman jeruk pamelo mencapai $\pm 4 \mathrm{~m}$ dengan jarak tanam $4 \times 3 \mathrm{~m}$. Jenis pembungkus yang digunakan adalah kantong plastik ukuran $24 \mathrm{~cm}$ berwarna bening. Plastik pemberongsong dilubangi pada bagian bawahnya untuk mengeluarkan air hujan di dalam plastik.

Peralatan yang digunakan meliputi timbangan analitik, luxmeter Smart Sensor AR 823, Corona thermo-hygrometer, chromameter Konica Minolta CR 10, hand refraktrometer Atago DUE-PSH 10, penetrometer controller MK VI, centrifuge 5410, spektrofotometer Schimadzu UV-1 800, vortex, alat-alat pertanian, dan alat-alat dalam analisis kimia.

Percobaan menggunakan Rancangan Acak Lengkap (RAL) dengan satu faktor yang dicobakan yaitu nisbah jumlah daun:buah yang terdiri dari empat taraf yaitu :

T1 : Aplikasi nisbah jumlah daun 50:1

T2 : Aplikasi nisbah jumlah daun 100:1

T3 : Aplikasi nisbah jumlah daun 200:1

T4 : Aplikasi nisbah jumlah daun 300:1

Setiap perlakuan diulang sebanyak 4 kali dengan menggunakan 1 tanaman untuk setiap ulangan sehingga terdapat 16 satuan percobaan.

Pelaksanaan penelitian ini dimulai dengan pemeliharaan tanaman dengan melakukan perontokan buah agar seragam, lalu memilih empat cabang setiap pohon. Masing-masing cabang dilakukan pemangkasan jumlah daun sesuai dengan perlakuan. Buah yang diberi label kemudian dibungkus dengan plastik pemberongsong agar tidak terserang hama dan penyakit. Pemangkasan daun dilakukan secara periodik agar jumlah daun tetap sesuai dengan perlakuan.

Kegiatan pemeliharaan lain yang dilakukan meliputi pengendalian gulma, pengendalian hama dan penyakit, serta pemupukan. Kegiatan pengendalian gulma dilakukan dengan menyemprotkan herbisida ke areal sekitar tanaman. Pengendalian dilakukan pada saat sebelum penelitian dan 2 bulan setelah penelitian berjalan. Pengendalian hama dan penyakit dilakukan satu kali ketika buah sudah berumur 9 MSP. Aplikasi pemupukan dilakukan dengan memberikan pupuk kandang, Urea, SP-36 dan $\mathrm{KCl}$. Pupuk diberikan secara melingkar mengelilingi tanaman dan ditutup kembali dengan tanah.

Variabel pengamatan pada penelitian meliputi pengamatan diameter horizontal buah per bulan (mm), diameter vertikal buah per bulan $(\mathrm{mm})$, bobot akhir buah (gram), diameter akhir buah (mm), kelunakan buah (mm $50 \mathrm{~g}^{-1} 5 \mathrm{~s}^{-1}$ ), Padatan Terlarut Total ( ${ }^{\circ}$ Brix) serta pengamatan Total Asam Tertitrasi (ml ATT $100 \mathrm{~g}^{\text {bahan }}{ }^{-1}$ ).

Data hasil pengamatan dianalisis menggunakan uji $\mathrm{F}$ untuk mengetahui adanya pengaruh antara perlakuan yang diuji. Jika terdapat pengaruh nyata, maka dilakukan uji lanjut Duncan Multiple Range Test (DMRT) pada taraf $\alpha=5 \%$. Perangkat lunak yang digunakan untuk analisis data adalah Microsoft Excel 2010 untuk rekapitulasi data dan SAS 9.0 untuk uji F. Data hasil warna buah hanya dianalisis secara deskriptif.

\section{HASIL DAN PEMBAHASAN}

\section{Kondisi Umum Percobaan}

Jeruk pamelo tumbuh dengan baik pada kisaran suhu $25-30{ }^{\circ} \mathrm{C}$ (Niyomdham, 1997). Suhu rata-rata di Darmaga per bulan adalah $26.3^{\circ} \mathrm{C}$ dengan kelembaban rata-rata per bulan sebesar $86 \%$. Curah hujan tinggi terjadi pada bulan Januari hingga Juni dengan nilai tertinggi yaitu $644 \mathrm{~mm}$ dan terendah $415 \mathrm{~mm}$.

Selama percobaan, tanaman dan buah mengalami serangan hama dan penyakit yang tergolong rendah. Hama yang menyerang pada buah dan tanaman antara lain ulat bulu, lalat buah, kutu putih, belalang dan kutu kebul. Ferrisia virgate adalah kutu putih yang banyak menyerang pada tanaman jeruk pada bagian daun dan buah. Kutu putih menimbulkan embun jelaga yang menyebabkan permukaan daun menjadi hitam dan permukaan daun tersebut terhalang dari sinar matahari langsung yang menyebabkan proses fotosintesis terganggu. Bactrocera spp adalah lalat buah yang banyak menyerang pada bagian buah jeruk pamelo. Serangan dari lalat buah berupa tusukan kecil pada buah sehingga kulit buah berlubang. Proses penusukan yang dilakukan lalat buah adalah meletakkan telur pada lapisan flavedo buah, sehingga buah akan cepat membusuk. Pengendalian hama tersebut dengan memetik buah jeruk yang terserang kemudian dibenam dalam tanah atau dibakar. Selain itu juga dilakukan pemasangan perangkat lalat buah yang menggunakan bahan aktif metyl eugenol sesuai anjuran.

Hasil rekapitulasi sidik ragam menunjukkan perlakuan nisbah daun buah pada percobaan memiliki pengaruh yang nyata terhadap diameter buah dan bobot buah, sedangkan pada peubah lainnya seperti pada bentuk buah, warna buah, kelunakan buah, PTT dan TAT menunjukkan pengaruh yang tidak berbeda nyata (Tabel 1). 
Tabel 1. Rekapitulasi sidik ragam nisbah daun buah terhadap kualitas buah jeruk pamelo pada 6MSP.

\begin{tabular}{lrc}
\hline Peubah & KK & $\begin{array}{c}\text { Analisis Sidik } \\
\text { Ragam }\end{array}$ \\
\hline Diameter 1 MSP & 9.81 & tn \\
Diameter 2 MSP & 9.15 & tn \\
Diameter 3 MSP & 8.86 & tn \\
Diameter 4 MSP & 7.35 & $*$ \\
Diameter 5 MSP & 6.54 & $*$ \\
Diameter 6 MSP & 6.56 & $*$ \\
Bobot Akhir Buah & 15.32 & $*$ \\
Bobot Kulit Buah & 25.91 & tn \\
Kelunakan Buah & 25.11 & tn \\
Kemulusan Buah & 14.51 & tn \\
Tebal Kulit Buah & 32.01 & tn \\
Padatan Terlarut Total & 14.08 & tn \\
Total Asam Tertitrasi & 5.43 & tn \\
Diameter 1 MSP & 9.81 & tn \\
\hline Kenang : MSP Mia
\end{tabular}

Keterangan : MSP : Minggu Setelah Perlakuan; KK : Koefisien Keragaman; *: berpengaruh nyata pada taraf $5 \%$; tn: tidak berpengaruh nyata.

\section{Pertumbuhan Buah Jeruk Pamelo}

Nisbah daun buah berpengaruh nyata terhadap diameter buah. Pada 4 MSP, ukuran diameter buah perlakuan 200 daun berbeda nyata terhadap perlakuan 50 daun. Perlakuan nisbah 100 dan 300 daun tidak berbeda nyata pada 4 MSP. Ukuran diameter buah perlakuan 300 daun pada 6 MSP memiliki ukuran paling besar yaitu $11.47 \mathrm{~cm}$ sedangkan pada perlakuan 50 daun memiliki ukuran paling kecil yaitu $10.44 \mathrm{~cm}$ (Tabel 2). Hal ini menunjukkan bahwa nisbah daun buah berpengaruh nyata terhadap diameter buah. Semakin tinggi jumlah daun maka hasil fotosintesis yang dihasilkan semakin banyak sehingga asimilat yang diserap oleh buah lebih banyak (sink) dan mendukung untuk perkembangan diameter buah. Goldschmidt (1999) juga menyatakan bahwa dengan jumlah asimilat yang lebih banyak diserap oleh buah, sehingga menunjang untuk proses pembesaran buah. Ketersediaan karbohidrat merupakan faktor pembatas dalam perkembangan buah. Kemampuan organ source dalam ketersediaan karbohidrat dalam jumlah yang tinggi menyebabkan meningkatnya ukuran buah. Menurut hasil penelitian Kalsum (2015) melaporkan bahwa ukuran dan bobot buah meningkat seiring dengan meningkatnya nisbah jumlah daun buah, hal ini menunjukkan bahwa terdapat hubungan korelasi positif antara total luas daun dan akumulasi karbohidrat daun terhadap bobot dan volume buah.

\section{Kualitas Buah Jeruk Pamelo}

Nisbah daun buah berpengaruh nyata terhadap diameter buah dan bobot buah, tetapi tidak berpengaruh nyata terhadap kelunakan buah, PTT, dan TAT (Tabel 3). Bobot buah pada perla kuan 100 daun tidak berbeda nyata, akan tetapi berbeda nyata pada nisbah 50 daun. Bobot buah pada perlakuan 200 dan 300 daun nyata lebih tinggi dibandingkan dengan perlakuan 50 daun.

Tabel 2. Pengaruh nisbah daun buah terhadap perkembangan diameter buah.

\begin{tabular}{lcccccc}
\hline \multirow{2}{*}{ Jumlah Daun } & \multicolumn{7}{c}{ Diameter Buah $(\mathrm{cm})$} \\
\cline { 2 - 7 } & $1 \mathrm{MSP}$ & $2 \mathrm{MSP}$ & $3 \mathrm{MSP}$ & $4 \mathrm{MSP}$ & $5 \mathrm{MSP}$ & $6 \mathrm{MSP}$ \\
\hline 50 & 8.44 & 8.89 & 9.19 & $9.67 \mathrm{~b}$ & $9.91 \mathrm{~b}$ & $10.44 \mathrm{~b}$ \\
100 & 9.92 & 10.15 & 10.21 & $10.30 \mathrm{ab}$ & $10.54 \mathrm{ab}$ & $10.66 \mathrm{ab}$ \\
200 & 9.43 & 10.17 & 10.70 & $11.27 \mathrm{a}$ & $11.48 \mathrm{a}$ & $11.46 \mathrm{a}$ \\
300 & 9.82 & 10.29 & 10.54 & $10.92 \mathrm{ab}$ & $11.29 \mathrm{a}$ & $11.47 \mathrm{a}$ \\
Uji F & th & th & tn & $*$ & $*$ & $*$ \\
KK $(\%)$ & 9.81 & 9.15 & 8.86 & 7.35 & 6.54 & 6.56 \\
\hline
\end{tabular}

Keterangan : MSP : Minggu Setelah Perlakuan; KK : Koefisien Keragaman; *: berpengaruh nyata pada taraf 5\%; tn: tidak berpengaruh nyata.

Tabel 3. Pengaruh nisbah daun buah terhadap kualitas jeruk pamelo

\begin{tabular}{lccccc}
\hline \multirow{2}{*}{ Jumlah Daun } & \multicolumn{5}{c}{ Kualitas } \\
\cline { 2 - 6 } & Diameter $(\mathrm{cm})$ & Bobot $(\mathrm{g})$ & Kelunakan Buah $\left(\mathrm{mm} 50 \mathrm{~g} \mathrm{~g}^{-1} 5 \mathrm{~s}^{-1}\right)$ & PTT $\left({ }^{0}\right.$ Brix $)$ & TAT (\%) \\
\hline 50 & $10.44 \mathrm{~b}$ & $471 \mathrm{~b}$ & 16.83 & 8.10 & 0.42 \\
100 & $10.66 \mathrm{ab}$ & $504 \mathrm{ab}$ & 14.58 & 8.25 & 0.43 \\
200 & $11.46 \mathrm{a}$ & $581 \mathrm{a}$ & 14.25 & 8.50 & 0.43 \\
300 & $11.47 \mathrm{a}$ & $597 \mathrm{a}$ & 14.04 & 9.00 & 0.44 \\
Uji F & $*$ & $*$ & tn & tn & tn \\
KK $(\%)$ & 6.56 & 15.32 & 25.11 & 14.08 & 5.43 \\
\hline
\end{tabular}

Keterangan : MSP : Minggu Setelah Perlakuan; KK : Koefisien Keragaman; *: berpengaruh nyata pada taraf 5\%; tn: tidak berpengaruh nyata. 
Bobot buah pada perlakuan nisbah 300 daun lebih berat dibandingkan dengan perlakuan lainnya. Bobot buah terendah terdapat pada perlakuan nisbah daun buah 50. Diameter buah pada nisbah daun buah 300 memiliki diameter tertinggi, sedangkan diameter nisbah daun buah 50 memiliki diameter terendah. Hal ini diduga karena banyaknya jumlah daun yang menyebabkan ketersediaan asimilat yang lebih banyak sehingga memiliki potensi yang lebih tinggi untuk menunjang pembesaran buah. Terdapat korelasi antara bobot buah dan diameter buah, semakin besar diameter buah maka semakin besar bobot buahnya.

Kelunakan buah tidak dipengaruhi oleh nisbah daun buah. Pada buah nisbah 50 daun memiliki kelunakan yang lebih tinggi dibanding buah nisbah 300 daun. Nisbah daun buah 50 memiliki kelunakan buah sebesar $16.83 \mathrm{~mm} 50 \mathrm{~g}^{-1}$ 5 detik $^{-1}$. Sedangkan pada buah nisbah 300 memiliki kelunakan buah terkecil yaitu sebesar $14.04 \mathrm{~mm} 50 \mathrm{~g}^{-1} 5$ detik $^{-1}$. Hasil sidik ragam dari kelunakan buah tidak berbeda nyata. Hal ini disebabkan bahwa kelunakan buah dipengaruhi oleh tingkat kemasakan buah. Menurut Santoso dan Purwoko (1995) kelunakan pada buah pamelo terjadi akibat pemecahan polimer karbohidrat, khususnya senyawa pektin dan hemiselulosa yang melemahkan dinding sel dan gaya kohesi yang mengikat sel bersama. Hal tersebut menyebabkan tekstur buah menjadi lebih lunak.

Perlakuan nisbah daun buah tidak berpengaruh terhadap PTT dan TAT. Kandungan gula dan asam pada buah jeruk pamelo berkaitan dengan tingkat kemasakan pada buah tersebut. Hal ini sejalan dengan penelitian Susanto et al (2013) bahwa nisbah daun buah pada jambu biji kristal tidak memberikan perbedaan yang nyata terhadap kandungan gula dan asam pada jambu biji kristal. Kalsum (2015) juga menyatakan bahwa kemanisan buah yang diindikasikan dengan PTT tidak dipengaruhi oleh nisbah jumlah daun buah.

\section{KESIMPULAN}

Nisbah daun buah berpengaruh nyata terhadap diameter buah dan bobot buah. Perlakuan nisbah daun buah 300 dan 200 daun memiliki ukuran diameter nyata lebih tinggi dibandingkan dengan perlakuan 50 daun, tetapi tidak berbeda nyata dengan perlakuan 100 daun. Perlakuan nisbah daun buah 300 memiliki bobot nyata lebih tinggi dibanding dengan perlakuan 50 daun, tetapi tidak berbeda nyata dengan perlakuan 100 dan 200 daun. Secara keseluruhan nisbah daun buah tidak berpengaruh terhadap warna buah, padatan terlarut total, total asam tertitrasi dan kelunakan buah.

\section{DAFTAR PUSTAKA}

Goldschmidt, E.E. 1999. Carbohydrate supply as a critical factor for citrus fruit develop ment and productivity. HortScience. 34 (6): 1020-1024.

Kalsum, U. 2015. Perbaikan kualitas jeruk pamelo (Citrus maxima (Burm.) Merr.) melalui pengaturan rasio jumlah daun:buah dan pemberongsongan buah. [Tesis]. Institut Pertanian Bogor. Bogor.

Latifah, T.S. 2000. Pengaruh umur panen dan periode simpan terhadap kualitas buah jeruk besar (Citrus grandis L.). [Skripsi]. Institut Pertanian Bogor. Bogor.

Liliandra, R. 2015. Pengaruh rasio daun:buah terhadap ukuran dan kualitas buah jambu biji (Psidium guajava L.) „Kristal“. [Skripsi]. Institut Pertanian Bogor. Bogor.

Nagy, S, P.E. Shaw, M.K. Veldhuis. 1977. Citrus Science and Technology Volume I: Nutrition, Anatomy, Chemical Composition and Bioregulation. The AVI Publishing Company, Wesport, Conneticut. p. 302-348.

Niyomdham, C. 1997. Citrus maxima (Burm.) Merr. Hal 153-157. dalam : E. W. M. Verheij dan Coronel RE. (Ed). PROSEA. Sumberdaya Nabati Asia Tenggara 2. P. T. Gramedia Pustaka Utama, Jakarta.

Riska, I.Y. 2012. Analisis preferensi konsumen terhadap buah jeruk lokal dan buah jeruk impor di kabupaten Kudus. J. Agrista. 1(2): 3-24.

Rattanapong, P. 2006. Effects of prunning and leafto-fruit ratio on growth, flowering and fruit quality of pummelo (Citrus maxima Burm. Merrill) cv. Hom Hat Yai. [Thesis Abstract]. http://kb.psu.ac.th/psukb/bitstream/2553/215 0/10/289676_ab.pdf. [24 April 2015].

Ryugo, K. 1988. Fruit Culture: Its Science and Art. John Willey\&Sons Inc, California.

Santoso, B.B, B.S. Purwoko. 1995. Fisiologi dan teknologi pasca panen tanaman hortikultura. Jurnal Indonesia Australia Eastern Universites Project, Jakarta. hal:185.

[Sekjen Kementan] Sekretariat Jenderal Kementerian Pertanian. 2013. Kinerja Perdagangan Komoditas Pertanian Volume 4 (2). Pusat Data dan Sistem Informasi 
Pertanian Sekretariat Jenderal Kementerian Pertanian, Jakarta.

Snyder, F.W., G.E. Carlson. 1993. Selecting for partitioning of photosynthetic products in corps. Jurnal Advances in Agronomy. 37: 47-69.

Sobir, Napitupulu. 2010. Bertanam Durian Unggul. Penerbit Swadaya, Jakarta.

Susanto, S. 2004. Perubahan kualitas buah jeruk besar (Citrus grandis (L) Osbeck) yang disimpan dan dibiarkan di pohon. Hayati. 11: 25-28.

Susanto, S., M. Melati, A. Junaedi. 2013. Optimasi source dan sink untuk meningkatkan produksi dan kualitas jambu kristal. Prosiding Seminar Hasil-Hasil PPM IPB Vol. I : 75-86.
Toh, J.J, H.E. Khoo, A. Azrina. 2013. Comparison of antioxidant properties of pomelo [Citrus grandis (L) Osbeck] varieties. International Food Research J. 20(4): 1661-1668.

Widodo, S.E, Zulferiyenn, I. Maretha. 2012. Pengaruh penambahan indole acetic acid (IAA) pada pelapisan kitosan terhadap mutu dan masa simpan buah jambu biji (Psidium guajava L.) crystal. Jurnal Agrotropika. 17(1): 14-18.

Winarno, F.G. 2002. Kimia Pangan dan Gizi. Gramedia Pustaka Utama, Jakarta.

Yuan, R., F. Alferez, I. Kostenyuk, S. Singh, J.P. Syvertsen, J.K. Burns. 2005. Partial defoliation can decrease average leaf size but has little effect on orange tree growth, fruit yield and juice quality. HortScience. 40 (7): 2011-2015. 